\title{
ACQUISITION OF PRACTICAL SKILLS IN DOMESTIC ELECTRICAL INSTALLATION: COMPUTER SIMULATION VERSUS DEMONSTRATION APPROACH
}

\author{
Nwineh, L. ${ }^{1}$ \& Okwelle, P.C. ${ }^{2}$ \\ ${ }^{1,2}$ Department of Vocational and Technology Education, \\ Rivers State University, Port Harcourt, Nigeria \\ Correspondence author email: nwineh.legborsi@ust.edu.ng
}

Received August 17 ${ }^{\text {th }}$, 2017; Accepted February $4^{\text {th }}, 2018$

\begin{abstract}
The study aimed to compare transfer of knowledge of domestic electrical installation acquired through two instructional approaches: a computer simulation instructional package called "wireman" and demonstration instructional approach for year two students of Vocational and Technical Education in a university in Nigeria. The study is based on the theory of identical elements. Adopting post-test-only control group design, the researchers post-tested 34 students taught using wireman and 34 students taught using demonstration teaching method with a 40-item domestic electrical installation competency checklist which was faced validated by three experts and subjected to Kuder-Richardson 20 formula to achieve an internal consistency reliability coefficient of .84. One research question and one hypothesis guided the study. The research question was answered using mean statistic. The hypothesis was tested using independent t-test at .05 alpha level of significance. Result showed that students taught with the wireman approach performed better than students taught with demonstration approach. It was therefore concluded that simulated instruction with wireman was effective in practical skill acquisition in domestic electrical installation for the participating students. Based on the result of the study, using simulation for instruction in domestic electrical installation is recommended.
\end{abstract}

Keywords: Practical skills acquisition, domestic electrical installation, learning transfer, simulation

DOI: https://10.30880/jtet.2018.10.01.004

Vol. 10, No.1 $\quad$ June 2018| ISSN 2229-8932 Journal of Technical Education and Training (JTET) | 45 


\section{INTRODUCTION}

One of the aims of technical and vocational education and training is to prepare individuals for the world of work (Alam, 2015). Based on this, students and trainees in this field of education sometimes alternate learning and training between school or training centres and workplace to expose them to practical and hands-on activities. In this process, they have the opportunity to relate theoretical knowledge gained from school to workplace experience (Nse, 2012 \& Nkwueze, 2011). Another way through which students of technical and vocational education and training are exposed to workplace experience is to engage in practical sessions in school workshops and labs after attending classroom instruction. One challenge with this kind of arrangement as noted by Eiríksdóttir and Jónasson (n.d.) is difficulty in transfer of learning between school and workplace.

Transfer of learning is the carrying over of knowledge or skill gained in one learning situation or environment to another (Santrock, 2011 \& Moreno, 2010). For instance, if a student learned series and parallel circuits connections from a physics class and is able to apply that knowledge to help understanding, when learning domestic electrical installation, transfer of learning will be said to have taken place. Transfer of learning is a very important factor in the field of education. It is described as an expected end of any teaching exercise (Cree \& Macaulay, 2001). As important as learning transfer in teaching and learning may be, there is a great concern about students' ability to transfer knowledge or skills learned between situations and environment. For example, Slavin (2006) reported that students often fail to transfer knowledge learned in real life environment. One factor responsible for failure to transfer knowledge in the view of Joseph (as cited in Abdul, 2015) is inability of students to connect previous learned tasks to the task being learned at the moment. It is therefore pertinent to seek ways of helping students transfer their knowledge gained in the classroom to demanding situations. For this to be achieved, the instructional design put in place is paramount. This is in accordance with the view of Olowa (2009) who posited that the teaching method employed by the teacher is one of the key determinants of the success of a teaching and learning process.

In technical and vocational education and training, one of the frequently used instructional strategies is demonstration. According to Ekeyi (2013), during demonstration, the teacher takes steps to perform the intended task or skill to be learned while students observe. Auwal (2013) posited that demonstration is a very viable instructional strategy for teaching subjects that are practically oriented. Faraday, Overton and Cooper (2011) also recommended demonstration as one of the teaching strategies to be employed in the effective teaching and learning of vocational education.

In Rivers State University of Science and Technology, Rivers State, Nigeria where this study was carried out, "Integrated Technical Workshop Practice" is one of the courses taken by year two students of Technical Education programme as part of requirement for bachelor's degree in Technical Education. In the course, domestic electrical installation is one of the modules taken. The aim of the module is to enable students acquire the practical knowledge, techniques and skills in carrying out electrical installation in residential buildings (National Board for Technical Education, 2001). It involves activities such as wiring connection for distribution board (DB), power and lighting circuits; connection through service cut out fuse, energy meter, circuit breaker, power change over to the distribution board; linking up the lighting and power circuits to the DB. The traditional instructional strategy employed during practical session in the workshop is demonstration method. The 
teacher uses available materials and tools to demonstrate how to carry out a task such as terminating electrical cables to students.

It is however observed, that in some situations, tools and materials may not readily be available for such demonstration to be carried out. Furthermore, in certain learning environment, a practical exercise may not be very safe or convenient for demonstration in the workshop. In such situations, learning may not be effective as students could only visualise topic learned based on explanation made by the lecturer. Consequently, transfer of learning when presented with physical electrical materials may be difficult. The researchers embarked on this study to find out if utilising demonstration in a computer simulated instructional package will aid students transfer knowledge learned from the computer simulation to a practical situation when they are given the physical materials and tools to carry out tasks related to domestic electrical installation. Slavin (2006) defined simulated software as a computer program that models a real-life phenomenon to enhance problem solving abilities and motivates interest in the areas concerned.

\subsection{Statement of the problem}

For some subjects or courses that require practical sessions in the workshops or laboratory, materials for practical exercise may not always be readily available. Furthermore, carrying out such practical exercise may not be very safe in the school environment. There is therefore need to seek for alternative instructional method for teaching such subjects or courses that have practical or hands-on component. Furthermore, the studies and literature reviewed so far on the utilisation of computer simulation in instruction were either carried out outside of Nigeria or not in the area of electrical installation. In fact, only a few research reviewed was carried out in the area of residential electrical wiring. Consequently, there was need for more study to fill the gap. The present study therefore sought to extend the study of the effect of simulated instructional package to the area of students' practical skill acquisition in domestic electrical installation.

\subsection{Purpose of the study}

The purpose of this study was to compare the effect of computer simulated instructional package and demonstration instructional approach on students' learning transfer in domestic electrical installation. Specifically, the study was designed to determine the difference in the practical skills acquired by students who were taught using demonstration and simulation approaches.

\subsection{Research Question}

The study sought to provide answer to the question: What is the difference in the practical skills acquired by students taught domestic electrical installation using demonstration and computer simulated approaches?

\section{$1.4 \quad$ Null hypothesis}

There is no significant difference in the practical skills acquired in domestic electrical installation by students taught demonstration through the simulated package and students taught with demonstration teaching method through the traditional way at .05 alpha level of significance. 


\section{LITERATURE REVIEW}

The literature review for this study was comprised three components which include theoretical framework, clarification of concepts and empirical review. The theory of identical transfer by Edward L. Thorndike and Robert S. Woodworth is presented. Furthermore, review of literature including empirical studies related to demonstration instructional approach and computer simulation in instruction is presented. Also, the review of literature on the concept of learning transfer is presented.

\subsection{Theoretical framework}

The present study focused on students' acquisition of practical skill in domestic electrical installation when taught using demonstration and computer simulated instructional approaches. It was intended to ascertain how these two instructional approaches would affect learning transfer between the class session and the real-life situation. The study was anchored on the theory of identical element proposed by Edward L. Thorndike and Robert S. Woodworth in 1901. The theory asserts that the extent knowledge and skill learned in one situation can be transferred between two contexts is dependent on the similarity between the two situations (Snowman, McCown \& Beihler, 2009). The idea behind the theory according to AlSagheer and Mohammed (2011) is the existence of identical elements in two learning contexts for transfer of learning to occur effectively between them. For instance, if the aim of a lesson is to enable students gain skill in connecting two electrical socket outlets (real life context), then students should be presented with learning environment that will enable them work with socket outlets and tools (learning context).

Materials and tools used in the physical demonstration instructional approach were materials such as electric plugs, socket outlets, consumer unit (distribution board), cables of different sizes, pliers, electric tester and others used for actual domestic electrical installation. All these materials were also modelled in the computer simulated application (wireman) used for the simulated instruction. Based on this, the theory of identical elements guided the study.

\subsection{Demonstration instructional approach}

In demonstration instructional approach, the teacher uses available instructional materials and tools to demonstrate to students the desire skills. It gives the students an opportunity to directly observe practical activities conducted in labs by the teacher, so that they can carry out same activity after the teacher. According to Slavin (2006), this opportunity helps to maintain information in their long-term memory. In turn, when information is maintained in long term memory, there is likelihood that it may be easily recalled and applied in future. Faraday, Overton and Cooper (2011) noted that demonstration instructional approach helps in building skill. Furthermore, Ekeyi (2013) viewed that demonstration instructional approach enhances students' motivation in situations where it is conducted by skilful instructors. Akinbobola and Afolabi (2009), described it as one that combines oral explanation of concepts together with hands-on step by step guide to build skill.

Three studies reviewed on demonstration in course of this study found demonstration instructional method effective in enhancing students' achievement and retention. In the study conducted by Akinbobola and Afolabi (2009) to determine the effects of guided discovery, demonstration and expository on students' achievement in physics in senior secondary schools in Nigeria, it was found that students taught with demonstration ranked second in physics performance. The researchers adopted non-randomise pre-test-post-test control 
group. The second study reviewed was carried out in secondary schools in Bauchi region of Nigeria by Auwal (2013) to find out the effect of demonstration and discussion instructional methods on students' retention of Agricultural Science knowledge. Using a pre-test and posttest control group quasi-experimental design, the researcher found demonstration instructional method to be more effective in the retention of Agricultural Science knowledge by students. In the third study reviewed under demonstration instructional method, Ekeyi (2013) conducted a study also to ascertain the effect of demonstration teaching method on students' performance in Agricultural Science secondary schools in Kogi state, Nigeria. The study employed a quasi-experimental research design and found demonstration instructional method to be more effective than the conventional lecture teaching method.

\subsection{Computer simulation/simulated instructional approach}

Computer simulation is defined by Slavin (2006) as a computer program that models a reallife phenomenon to enhance problem solving abilities; motivates and actively engages students in class activities. Furthermore, Thomas and Hooper (as cited in Liao and Chen, 2007) described computer-based instructional simulation as a computer program that contains a model of a real life theoretical system which can be manipulated by learners. Aldrich (as cited in Ezeudu and Ezinwanne, 2013) described simulation as a tool used to facilitate learning through representation and practice in a repeatable and focused environment. In this paper, simulated instructional package refers to instructions packaged with a computer program aimed at enhancing learning and also engaging learners in carrying out practical activity in a virtual environment. Bell and Smetana (2008) described computer simulation as a dynamic computer-generated representation of a real-world components, phenomena, or processes. Similarly, Kassa and Damtie (2007) see computer simulation as a computergenerated version of a real equipment-based experiment.

Simulation is one of such technologies being utilised today to enhance teaching and learning in various fields of study. For example, Fenrich (n.d.) reported that computer simulation has been used at the British Columbia Institute of Technology, Canada, to train aircraft mechanics on how to disassemble, assemble, and inspect aircraft engines; used by carpenters to learn how to build roofs; used by plumbers to learn how to troubleshoot hot water heating systems, backflow prevention systems and to adjust the air/gas mixtures in furnaces. Fenrich further stated that simulation is used by fish canners to learn how to identify flaws in cans and the cause of those flaws; used by nurses to learn how to handle patients with spinal injuries; used by doctors to learn how to diagnose diseases and by teachers to learn how to teach. Furthermore, Heinich, Molenda and Russell (as cited in Liao and Chen, 2007) reported the use of computer simulations for job training in colleges of management in the United States of America. In the view of Doering and Veletsianos (2009), computer simulation enhances students' participation; makes experimentation safe and the impossible possible; saves cost and allows for multiple repetitions of an exercise. Computer simulation can be used to provide a way of learning vocational skill through distance learning; serves as a solution to limited or expensive equipment and materials (Fenrich n.d.). Literature reveals some positive impact of computer simulation on instruction. Such impact includes provision of opportunity for students to engage in activities that they may not have been able to engage, in the absence of physical practical materials; enhance students' performance and learning achievement; help students to acquire practical skill just as the physical practical activities would have done Michael (as cited in Liao and Chen, 2007). 
In a critical review study conducted by Boutefnouchet and Laios (2016) to determine the transferability and retention of skills learned from arthroscopic simulation to operating theatre, it was found that the simulation was successful in improving performance of basic tasks. Guy and Lownes-Jackson (2015) carried out an experimental study to compare the effect of computer simulation and the traditional instructional method on students' achievement in microcomputer application course. The study which was conducted in College of Business at Tennessee State University found that students who were taught with computer simulation performed better than students taught with traditional method. In a research conducted to determine the impact of computer simulated direct current circuit physics lessons on students' achievement, group Interaction and Attitude, Kassa and Damtie (2007) found that students who used computer simulation gained mastery of concepts in electric circuit concept evaluation more than students who used traditional equipment-based experiment in the learning of direct current circuits. Furthermore, they found that students who used simulation performed significantly higher in a test to set up practical equipment than students who used the traditional equipment-based experiment in learning. Furthermore, Ezeudu and Ezinwanne (2013) found that using simulation increased students' achievement in chemistry. Similarly, in the study Liu and Su (2011) to determine the impact of computer simulation on students' achievement in the area of residential electrical wiring it was found that students exposed to the computer simulation performed better than those the traditional methods of teaching. The study adopted a quasi-experimental design. On the contrary, in the study of Bayrak (2007) to compare the effect of computer simulation and laboratory based instruction on students' achievement in electrical circuit in Turkey using experimental design, no significant difference was found between the two instructional strategies on students' scores.

\subsection{Learning transfer}

Learning transfer according to Slavin (2006) is the utilisation of knowledge learned in one situation in another situation. For instance, if a student applies knowledge fraction learned in mathematics in solving problems of effective resistance in a parallel circuit in electricity, transfer of learning is said to have taken place. AlSagheer and Mohammed (2011) described transfer of learning as a process through students apply knowledge acquired from the learning of one task to the learning or performance of another task. Transfer of learning is a very important concept in the field of technical and vocational education and training. This is due to the fact that students or trainees in this form of education are trained to acquire work skills. As a result of this, knowledge learned from school should be applied in the workplace while working. Sometimes, students in the area of technical and vocational education and training are also engaged in one form of industrial experience or the other. It is also expected that they will apply knowledge learned from the workplace in subsequent learning situations in the classroom. It is therefore pertinent that instruction should be structured to enhance transfer of learning from classroom situation to workplace situation.

There are different types of learning transfer. These include positive and negative transfer. While positive transfer involves a situation where learning a new task is positively influence by what has been learned before, negative transfer involves a situation where learning a new task is hindered by what has been learned before (Moreno, 2010). Moreno further described two types of positive transfer which are known as specific and general transfer. Specific transfer is the ability to apply or relate learned knowledge from one situation to a similar situation and general transfer is the ability to apply what was learned in a particular situation to some other general situation. Other types of transfer described by 
Santrock (2011) include near transfer, far transfer, low-road and high-road transfer. Near transfer is similar in definition to specific transfer since it also talks about both learning and transfer situation being similar. Furthermore, far transfer is similar to general transfer as it looks at learned and transfer situations being different. Low road transfer is the situation where a knowledge learned in one situation is transferred automatically to a new situation unconsciously. On the other hand, high-road transfer is the situation where knowledge learned from one situation is transferred to another situation by a conscious effort.

\section{METHODOLOGY}

The study adopted post-test only control group design. Ary, Jacobs and Sorensen (2010) described this as a type of experimental design in which the researcher randomly assigns subjects to both experimental and control groups, administers a post-test on both groups after treatment (see Table 1). Furthermore, Gall, Gall and Borg (as cited in Denson and Hill, 2010) noted that this type of design is useful in situations where pre-testing may affect result of post-test or behaviour of research participants. Students involved in the study were those taking domestic electrical installation. Administering a pre-test on them before treatment could possibly affect result of the post-test as some of them could discuss among themselves, the way they did their connections during the pre-test. This way, result may be influenced. Although, a potential threat to the validity of this design is mortality, however, this was not a problem since the group size for the study remained constant throughout the study and the duration of the study was only three weeks.

Table 1: Post-test only Control Group Design

\begin{tabular}{lcccc}
\hline Group & Assignment & $\boldsymbol{n}$ & Treatment & Post-test \\
\hline Experimental & Random & 32 & Instruction with Wireman & DEICC* \\
Control & Random & 32 & Instruction with electrical diagrams & DEICC $^{*}$ \\
\hline
\end{tabular}

*Domestic Electrical Installation Competency Checklist

\subsection{Population and sample}

Population for the study was 64 students of Technical Education program of the Department of Vocational and Technical Education of the Rivers State University, Port Harcourt, Nigeria, who took the course, 'Integrated Technical Workshop Practice'. All 64 students were used for the study as it was manageable.

\subsection{Instrumentation}

A 40 item Domestic Electrical Installation Competence Checklist (DEICC) developed by the authors of this paper for data collection and validated by three experts. DEICC consisted of four parts which measured acquisition of practical skill in power circuits; lighting circuits; wiring connection from service head to the distribution board; and Linking up lighting and power circuits to the distribution board/connection to earth. Direct observation was used by the researchers to evaluate participants on the competencies expected of them. If an expected competency was found to have been acquired, YES was ticked against it and if otherwise, a NO was ticked. Kuder-Richardson formula 20 was used to determine the internal consistency reliability of DEICC by administering it to a sample of 20 students and then data subjected to Kuder-Richardson formula 20 to obtain a reliability coefficient of .84 . 


\subsection{Procedure}

Before treatment was applied to the groups, the 64 students were randomly assigned to two groups: experimental and control groups consisting of 32 students each. Random assignment into the two groups was done by randomly assigning students with higher level of performance to the two groups and also randomly assigning students of lower level of performance to the two groups (experimental and control). The experimental group was taught using wireman (See description in section 3.4). The instructor used wireman to carry out the different tasks contained in the content of instruction. The students were given the opportunity to also practice the connection with wireman. They also took notes as references for them when they would carry out the practical with materials. On the other hand, the control group was taught using demonstration method. In this method, the instructor drew wiring diagrams on the board and demonstrated connections while the students observed and took notes as reference for them when they would carry out the practical with materials. The period of this instruction was three weeks for both groups. The content of instruction for these two groups was the same consisting of four modules which included the four parts covered in the checklist. After each module, the students in both groups were immediately presented with the practical materials for that module to carry out practical exercise. DEICC was used for data collection and they were evaluated by direct observation. After this exercise, the instrument was collected for data analysis. Mean was used to answer the research question while t-test was used to test the hypothesis at .05 alpha level of significance. Data analysis was carried out using Microsoft Excel the null hypothesis was rejected if p-value was less than .05 .

\subsection{Description of wireman}

The simulated instructional package used for this study is called "wireman". It is a software application that simulates the practical activities carried out by teachers and students in the teaching and learning of domestic electrical installation. It consists of interfaces used for practical exercises of various kinds in domestic electrical installation with the first interface (See figure 1) after login page as the access interface to other interfaces. Each of the interfaces aside the first interface is divided into two major parts.

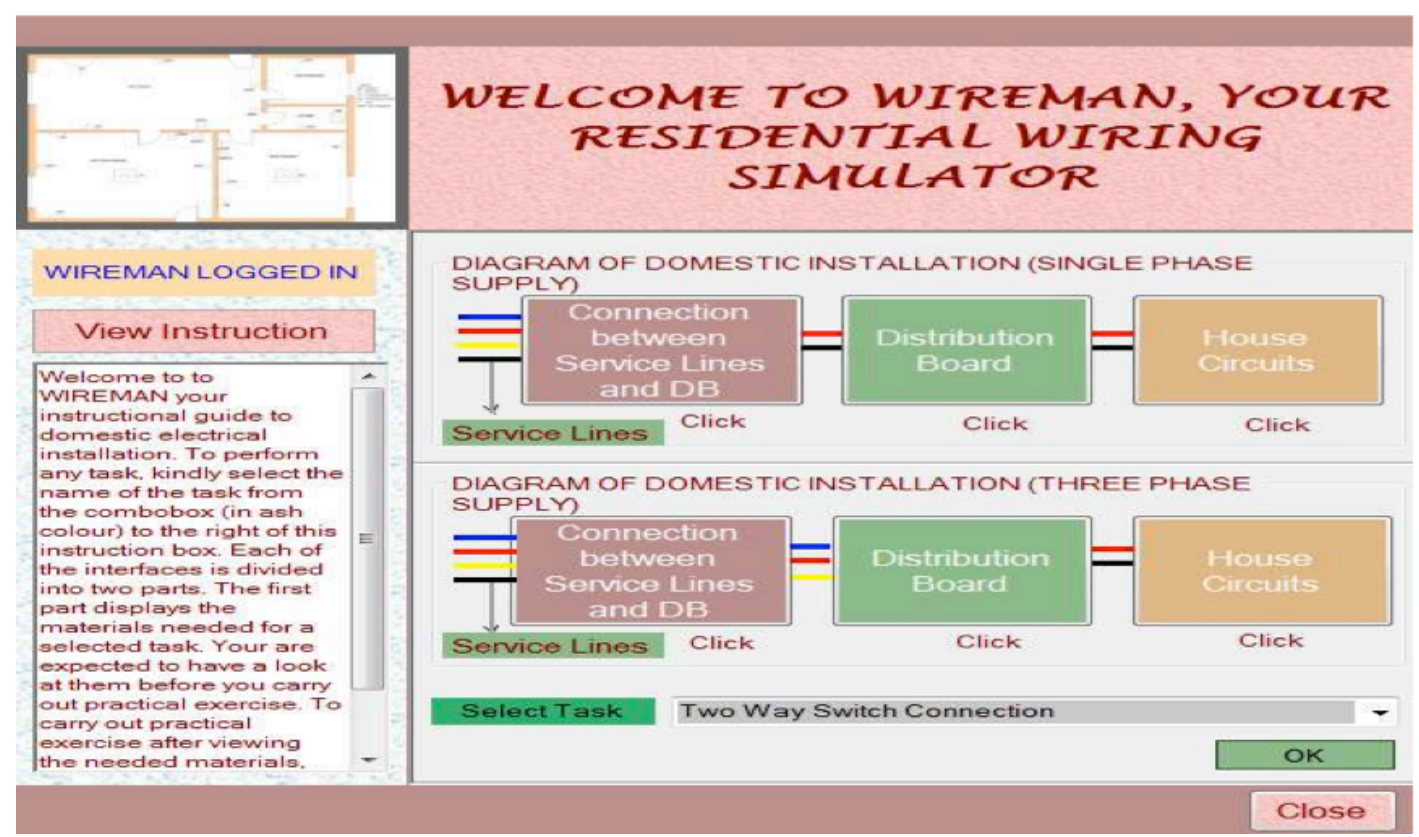

Figure 1: Front interface of wireman (Nwineh, 2013:333) 
The first part displays materials needed to carry out a particular practical exercise. The teacher is expected to use this part to show and explain to students' materials and tools needed for an exercise. The second part handles carrying out the practical exercise using the application (Nwineh, 2013).

\section{RESULTS}

This section presents result of data collected for analysis. The result is presented in Table 2 below. The column showing mean values for the experimental and control groups presents result to answer the research question while the columns showing t-values and p-values present result about the hypothesis.

Table 2: Test of Significance for Null Hypothesis

\begin{tabular}{lccccccccc}
\hline Group & Mean $(\boldsymbol{M})$ & $\boldsymbol{S D}$ & $\boldsymbol{N}$ & $\boldsymbol{d f}$ & $\boldsymbol{t}_{\text {cal }}$ & $\boldsymbol{t}_{\text {crit }}$ & $\boldsymbol{p}$-value & Effect Size & Decision \\
\hline Experimental & 79.06 & 7.06 & 32 & \multirow{2}{*}{62} & 6.56 & 2.00 & 0.00 & \multirow{2}{*}{1.64} & Significant \\
Control & 66.95 & 7.69 & 32 & & & & & & \\
\hline
\end{tabular}

Source: Field study, 2014

Result from Table 2 indicates a mean score of $\mathrm{M}=79.06$ for the experimental group and a mean score of $\mathrm{M}=66.95$ for the control group. This shows that students who were taught domestic electrical installation with wireman performed better than students taught domestic electrical installation with demonstration instructional method. The test of significance for the hypothesis $\mathrm{t}(62)=6.56, \mathrm{p}<.05$. Based on this, the null hypothesis that "there is no significant difference in the practical skills acquired in domestic electrical installation by students taught using wireman and students taught using demonstration method" was rejected. This result shows that the scores of experimental and control groups were significantly different. The effect size $(E S=1.64)$ indicates that the experimental group scored approximately 2 standard deviation higher than the control group.

\subsection{Discussion}

Table 2 reveals that on the average, students taught using wireman, the simulated instructional package for teaching and learning of domestic electrical installation gained practical skill in domestic electrical installation than those taught using diagrams of wiring connection on board or charts. This result is in conformity with the results obtained by Kassa and Damtie (2007) who found that students who used computer simulation in learning gained mastery of concepts in electric circuit concept evaluation and practical skill in setting up equipment for direct current circuit more than students who used real practical equipment in learning. The result is also consistent with the findings of Ezeudu and Ezinwanne (2013) that the achievement of students in chemistry increased after being taught with computer simulation. Furthermore, the result of the study is consistent with the results of Boutefnouchet and Laios (2016) and Guy and Lownes-Jackson (2015). On the contrary, this result negates the result obtained by Bayrak (2007) who found that there was no significant difference in the effectiveness of using computer simulated and laboratory instructions. The result implies that simulated instructional package has great promise for teaching and learning in acquisition of practical skills in technical and vocational education and training. The result of this study could have been from the saying: "practice makes perfect". Students who used the simulated instructional package had opportunity to do some virtual practice with the application. In this process, somehow, retention and transfer may have taken place. 
So, when faced with real life situation they may have been able to recall better their control group counterparts.

\section{CONCLUSION AND RECOMMENDATION}

The result from the study showed students who were taught domestic electrical installation with wireman performed better than students taught domestic electrical installation with demonstration instructional method. It was therefore concluded that simulated instruction with wireman was effective in practical skill acquisition in domestic electrical installation for the participating students. It is therefore recommended that teaching and Learning with technologies such as computer simulators should be encouraged in areas where the learning outcome is to acquire practical skills but instructional tools are not available. Further research should also be carried out to find out the impact of using computer simulators on constructs such as retention, understanding of process concepts in technical and vocational education and training.

\section{Reference}

Adalikwu, S.A., \& Iorkpilgh, I.T. (2012). The influence of instructional materials on academic performance of senior secondary school students in chemistry in Cross River State. Global Journal of Educational Research, 12(1). Abstract retrieved April 4, 2014 from http://www.ajol.info/index.php/gjedr/article /view/91018

Abdul, H. (2015). Training intervention and strategies for positive learning transfer. Journal of Resources Development and Management. 11 107-114.

Alam, N. (2015). The role of technical vocational education and training in human development: Pakistan as a reference point. European Scientific Journal, 11(10). 35-50.

AlSagheer, A., \& Mohammed, B.H. (2011). The transfer of learning: exploration of benefits and perspectives in the state of Kuwait. International Journal of Management \& Information Systems, 15(2), 39-48.

Ary, D., Jacobs, C.L., \& Sorensen, C. (2010). Introduction to research in education (8th ed.). Belmont, CA: Wadsworth, Cengage Learning.

Auwal, A. (2013). Effects of teaching method on retention of agricultural science knowledge in senior secondary schools of bauchi local government area, Nigeria. International Journal of Science and Technology Educational Research, 4(4), 63-69.

Bayrak, B. (2007). To compare the effects of computer based learning and the laboratory based learning on students' achievement regarding electric circuits. The Turkish Online Journal of Educational Technology, 6(1), 1-9.

Bell, L.R., \& Smetana, K.L. (2008). Using computer simulations to enhance science teaching and learning. In R.L. Bell, J. Gess-Newsome, \& J. Luft (Eds.) Technology in the secondary science classroom (pp. 23). United States of America: NSTA press.

Boutefnouchet, T. \& Laios, T. (2016). Transfer of arthroscopic skills from computer simulation training to the operating theatre: a review of evidence from two randomised controlled studies. SICOT J 2(4), 1-8. DOI: $10.1051 / \operatorname{sicotj} / 2015039$

Cree, E.V., \& Macaulay, C. (2001). Transfer of learning in professional and vocational education. New York, NY: Routledge.

Denson, D.C., \& Hill, B.R. (2010). Impact of an engineering mentorship program on African-American male high school students' perceptions and self-efficacy. Journal of Industrial Teacher Education, 47(1), 105. Retrieved from http://scholar.lib.vt.edu/ejournals/JITE/v47n1/pdf/v47n1.pdf

Doering, A., \& Veletsianos, G. (2009). Teaching with instructional software. In M.D. Roblyer \& A. Doering (Eds.) Integrating educational technology into teaching (pp. 76-95). Upper Saddle River, NJ: Pearson Education.

Eiríksdóttir, E. \& Jónasson, T. J. (n.d.). Vocational education and training at school and at the workplace the Icelandic case. School of Education, University of Iceland. Available at www.vkhkee/.../School $\% 20 \mathrm{of} \% 20$ Education, \%20University\%20of\%20Iceland.pdf accessed on 8 September, 2016

Ekeyi, N.D. (2013). Effect of demonstration method of teaching on students' achievement in agricultural science. World Journal of Education, 3(6), 1-7. 
Ezeudu, F.O., \& Ezinwanne, O.P. (2013). Effect of simulation on students' achievement in senior secondary school chemistry in Enugu east Local Government Area of Enugu State, Nigeria. Journal of Education and Practice, 4(19), 84-85. Retrieved from http://www.iiste.org/Journals/index.php/JEP/article/ viewFile/7864/7920

Faraday, S., Overton, C. \& Cooper, S. (2011). Effective teaching and learning in vocational education. London: LSN.

Fenrich, J.P. (n.d.). Effective vocational computer-based training. Retrieved April, 6, 2014 from http:// wikieducator.org/images/d/d5/PID_357.pdf

Guy, S.R., \& Lownes-Jackson, M. (2015). The use of computer simulation to compare student performance in traditional versus distance learning environments. Issues in Informing Science and Information Technology, 12, 95-109. Retrieved September 7, 2016 from http://iisit.org/Vol12/IISITv12p095109Guy1767.pdf

Kassa, T., \& Damtie, B. (2007). The impact of computer simulated direct current circuit physics lessons on achievement, group interaction and attitude of students: The case of 2007 first year physics majoring students at Bahir Dar University. The Ethiopian Journal of Higher Education 4(1), 26-41. Retrieved April 4, 2014 from www.aau.edu.et/nprc/Documents/ AtoTsegaye\%20\&\%20Dr.Baylie.doc

Liao, Y., \& Chen, Y. (2007). The effect of computer simulation instruction on student learning: A meta-analysis of studies in Taiwan. Journal of Information Technology and Applications 2(2), 69-70. Retrieved March 28, 2014 from http://140.126.5.184/Jitaweb/publish/vol2num2/04The $\% 20$ Effect $\% 20$ of $\% 20$ Computer $\% 20$ Simulation $\% 20$ Instruction $\% 20$ on $\% 20$ Student $\% 20$ Learning0.pdf

Liu, H-C., and Su, I-H. (2011). Learning residential electrical wiring through computer simulation: The impact of computer-based learning environments on student achievement and cognitive load. British Journal of Educational Technology, 42(4), 598-607. doi:10.1111/j.1467-8535.2009.01047.x

Moreno, R. (2010). Educational Psychology. Hoboken, NJ: John Wiley \& Sons, Inc.

National Board for Technical Education. (2001). Electrical Installation and Maintenance Work National Technical Certificate (NTC) and Advanced National Technical Certificate (ANTC) Curriculum and Course Specifications. Available at http://unesdoc.unesco.org/ images/0016/001613/161329e.pdf accessed on 08 January, 2014

Nkwueze, F.N. (2011). Impact of students' industrial work experience scheme (siwes) on development of graduate employability skills. Nigerian Vocational Association Journal. 16(1), 118-124.

Nse, J. (2012). Evaluation of Students' Industrial Work Experience Scheme (SIWES) in Library School: The Federal Polytechnic Nekede Experience. Library Philosophy and Practice. Available at http://www.webpages.uidaho.edu/ mbolin/nse.htm accessed on 16 September, 2015

Nwineh. L (2013). Design of a Simulated Instructional Package for Teaching and Learning of Domestic Installation. Nigerian Vocational Association Journal, 18(1), 327-337.

Olowa, W.O. (2009). Effect of the Problem Solving and Subject Matter Approaches on the Problem Solving Ability of Secondary School Agricultural Education. Journal of Industrial Teacher Education, 46(1), 33-47. Available at http://scholar.lib.vt.edu/ ejournals/JITE/v46n1/pdf/olowa.pdf accessed on 25 June, 2012

Santrock, W.J. (2011). Educational psychology (5th ed.). New York, NY: McGraw-Hill.

Slavin, E.R. (2006). Educational Psychology theory and practice (8th ed.). Boston, MA: Pearson Education, Inc.

Snowman, J., McCown R., \& Biehler R. (2009). Psychology Applied to Teaching (12th ed.). Boston, MA: Houghton Mifflin Company. 